\title{
Preliminary design criteria of prestressed concrete structures
}

\author{
Sevgi Lökce*1(D), Erşan Göksu² (iD) \\ ${ }^{1}$ Atılim University, Department of Architecture, Ankara, Turkey \\ ${ }^{2}$ MEG Technical Consultants, Marly, Switzerland
}

\begin{abstract}
Although not the only option, reinforced concrete is the most widely used technique in the world for building structures. Joseph Monier, the owner of an important nursery in Paris deserves the credit for making the first practical use of reinforced concrete in 1867. Throughout the entire period of $1850-1900$, relatively little was published as the engineers working in the reinforced concrete field considered construction and computational methods as trade secrets. One of the first publications that might be classified as a textbook was that French engineer, Armand Considere, in 1899, who had been chief engineer with the Ponts et Chaussees in France. In 1903, with the formation in the United States of a joint committee of representatives of all organizations interested in reinforced concrete, uniform applications of the knowledge to design were initiated. Since then, engineers and especially architects were able to make the preliminary designs called "Preliminary Dimension Estimation" as well as "Reinforcement Estimation" through the "Thump Rule Method" in Reinforced Concrete Structures. By the beginning of new era of prestressed concrete structures, especially in High Rise Buildings the dimension estimations well as reinforcement estimation through Thump Rules of Reinforced Concrete Structure were not be adequate. In this paper, the preliminary design criteria of prestressed concrete structures are discussed in several conceivable aspects. However, while this is the simplest method to check the total estimated dimensions and quantity of prestressing as well mild reinforcement, it is the least accurate and requires considerable experience to break down the measures vs the amounts down to the standard method of measurement requirements. The prestressing of concrete has several advantages as compared to traditional reinforced concrete (RC) without prestressing. A fully prestressed concrete member is usually subjected to compression during service life. This rectifies several deficiencies of concrete as material of construction and prestressing technology.
\end{abstract}

\section{Keywords}

Reinforced concrete structure; Prestressed concrete structure; Minimum dimensions; Bending; Punching; Necessary mild reinforcements.

Received: 26 September 2019; Accepted: 23 January 2020

ISSN: 2630-5763 (online) C 2020 Golden Light Publishing All rights reserved.

\section{Introduction}

Prestressed concrete systems can be defined as creating a compression zone of a structural member in the region, where tensional stresses are expected to appear, so that the whole section under the total load combination receives a stress level less than concrete compressive strength. Special attention has to be paid to avoid the stress increases in the section above allowable ones.

The prestressed concrete is not the only instance of prestressing, and in daily life, such a practice prestressing is used to carry books before the

\footnotetext{
Corresponding author

Email: slokce@gmail.com
} 
development of prestressed concrete as seen in Fig. 1.

A prestressed concrete structure is different from a conventional reinforced concrete structure due to the application of an initial load on the structure prior to its use. The initial load or prestress is applied to enable the structure to counteract the tensional stresses arising during its service period. Generally, there are two types of prestressed applications in the technology field. The first one is Pretensioning System, which is produced in factories, in prestressing beds, and the second one is Posttensioning System, which are mostly in-situ applications [2]. In this paper, only one of the two types of prestressed concrete applications, posttensioning system will be discussed.

\subsection{Advantages of prestressed concrete}

Prestressed concrete systems have brought lots of advantages above all as construction material as well as construction technology:

i. As material of construction

- The thickness reduction and crossing large spans

- Freedom - of - design

- Reduction of the total height of the building and additonal floors for the same allowable height

- Reduction in mild reinforcement about 20$50 \%$

- Reduction of total cost and duration of construction

ii. As prestressing technology

- Monolithic structural members vs systems

- Reduction in dead loads; punching + earthquake

- Displacements

- Rate of change in formwork

- Easy and practical execution

- Simple - high quality - specialized workmanship

- Easy to control

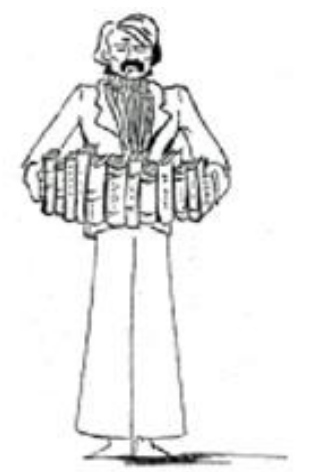

Fig 1. Man carrying books using prestressing

From the construction material point of view, using prestressed concrete reduces the slab and beam thickness. [3] Reduced slab thickness enables additional floors to be built for the same allowable building height. Prestressed concrete also allows crossing large spans. This is a reflection of freedom-of-the design concept proposed by Le Corbusier. The example shown in Fig. 2 illustrate that this feature improves freedom of design. The use of high strength steel reduces mild reinforcement requirement. Therefore, the cost and construction time of projects can be reduced. As a construction technology, prestressed concrete improves structural systems by producing monolithic structural elements, reducing dead loads and limiting displacements. Prestressed concrete designs also have highly controllable construction sequences, which allow practical execution. [4]

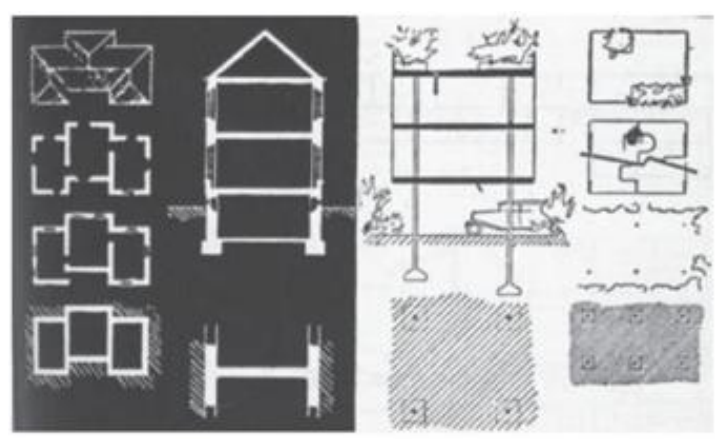

Fig 2. Freedom - of - design concept of Le Corbusier adopted from Robertson (1940) 


\section{Value engineering / system vs member optimization}

Value engineering is the systematic application of function-oriented techniques by a multi-disciplined team to analyze and improve the value of a product, process or service. [1]

\subsection{System vs member optimization}

As it is seen in Fig. 3, the number of columns is inversely proportional with the thickness of flat slabs similar to the bridges as bridge piers and bridge deck.

Optimization of slabs, starts with a preliminary concept study by architects. One the one hand, the freedom - of - design is an important parameter for architects. On the other hand, the price of the structure is a dominant factor for investors. As the number of columns increases, slab thickness could be reduced and replaced with a thinner slab, thereby the decreasing slab costs. Otherwise the column costs increase the freedom - of - design dream of architect should be abolished. To find an optimum solution, one has to set up the axes in such a way that, freedom of design can be preserved and optimization of column numbers to slab thickness can be attained.
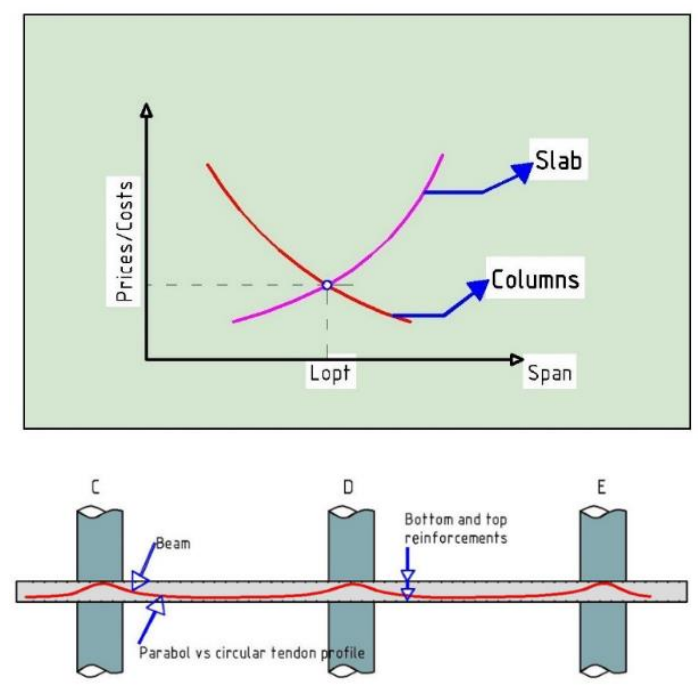

SECTION
In order to optimize the thickness of slab which has a great influence on the spans between the columns, i.e. number of columns, one should take to account three main parameters: concrete, mild steel and prestressing cables. If the mild steel and prestressing cables together contribute to the tensional forces and the concrete as the compression force, the two parameters of the optimization study will be eligible.

The concrete amount is depending on the width, and the height of the rectangular section. As it is known from reinforced concrete (RC) principles, the amount of the 'tensional member' is inversely proportional with the height, i.e. volume of the concrete. As the height of a rectangular section increases, the number of tensional members decreases. Optimum height will be established as it is seen in Fig. 4, where concrete prices and the tensional members prices reach an optimum.

The problem is to find out the economical combination of mild steel and the prestressing cables. The proportion of the amount of PC cables to the RC steel depends on, first, the quality of the two construction materials and, second, their unit prices. Even though elastic modules of PC are nearly fixed all over the world, the elastic modules of RC steel depend on the standards of each country. Yet, the most important factor is their unit prices which determine the difference between them. In industrial countries, where PC cables are produced, the difference of prices is not so high as in developed countries, where PC cables should be imported from. These proportions are the main parameter to decide the amount of PC cables.

$\mathrm{PPC} / \mathrm{PRC}=\mathrm{g}$

After determining the amount of minimum reinforcement as the described by national standards and norms against cracks, creep and shrinkage by utilizing the above-written proportion, it will be easy to estimate the minimum amount of PC cables. In case of large spans and/or heavy loadings, the amount of PC cables should be increased.

Fig 3. System optimization 

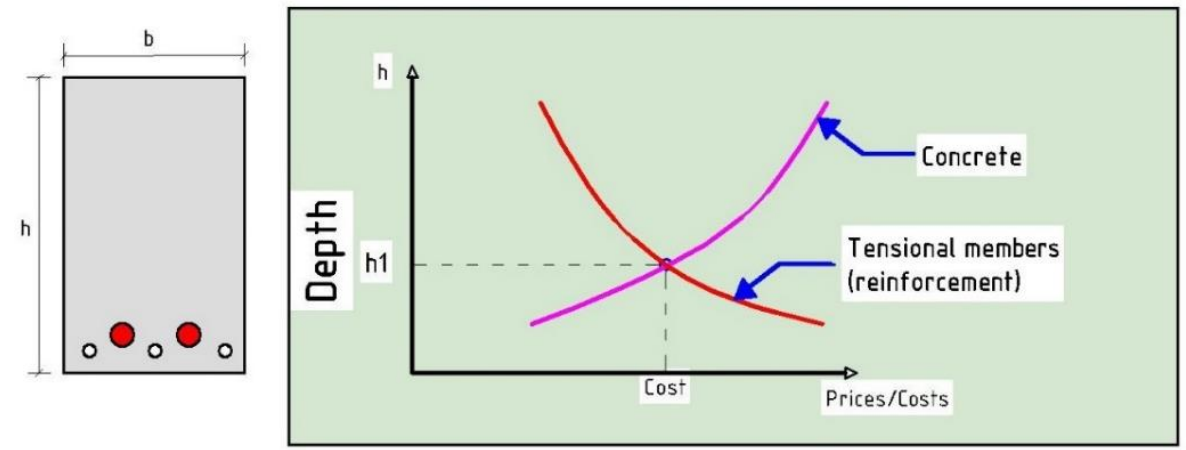

Fig 4. Section / Member optimization

Amount of tensional members estimation (Thumb Rule Method):

Heavy industrial $=130 \mathrm{~kg} / \mathrm{m}^{3}$

Commercial $\quad=100 \mathrm{~kg} / \mathrm{m}^{3}$

Institutional $\quad=90 \mathrm{~kg} / \mathrm{m}^{3}$

Residential $\quad=85 \mathrm{~kg} / \mathrm{m}^{3}$

If we assume the minimum tensional reinforcement as $0.015 \%$ of the concrete section as $40 \mathrm{~kg} / \mathrm{m}^{3}$, the amount of PC cables will be $\left(130-140 \mathrm{~kg} / \mathrm{m}^{3}\right) / \mathrm{g}$ $\mathrm{kg} / \mathrm{m}^{3}$ depending on the countries and their unit pieces for each tensional material.

\section{Steps to be taken for preliminary design}

\subsection{Geometry}

\subsubsection{Systems}

Despite a very recent philosophy of architects based on the function follows form principle, the main principle of architecture 'form follows function' is as usual valid and important for engineers, who learned that principle at school. Instead the form follows function is complemented as structure follows form by structural engineers. As architects create their own forms depending on the function, they are supposed to take into account the structural system from all conceivable aspects, not only as material but also as structural systems.

As described above, the mesh of their support system should conform with the technology of new material and construction methods. In system optimization, columns and the spacing between them should give the best possible slab thickness as far as the economy is concerned.
The sizes of vertical and structural members can be optimized to keep the volume of concrete for the entire superstructure, inclusive of walls and lift cores, to be in the region of 0.4 to $0.5 \mathrm{~m}^{3}$ per square meter. In Fig. 5 it is considered to be economical and comparable to an optimum design in conventional beam and slab systems.

For simple supported systems, the thickness of slabs for preliminary design purpose rules of thumb is developed:

Concrete slabs: $L / h=45-36$ depending on the loading case.

Here, $L$ is the average value of the spans, i.e. $L=\sqrt{L_{x}^{2}+L_{y}^{2}}$ and $h$ is the slab thickness.

For continuous systems, the thickness of slabs could be less than the value given above.

For flat slabs the thickness of slab can be seen from the Figs. 6-8.

\subsection{Loadings}

Conventionally, building regulations require that structures be designed and built to withstand all load types that they are likely to face during their lifecycle. [3]

\subsubsection{Dead loads (DL)}

Dead loads, also known as permanent or static loads, are those predominantly associated with the weight of the structure itself, and remain stationary and relatively constant over time. Dead loads may include the weight of any structural elements, permanent non-structural partitions, immovable fixtures such as plasterboards, built-in cupboards, and so on. 


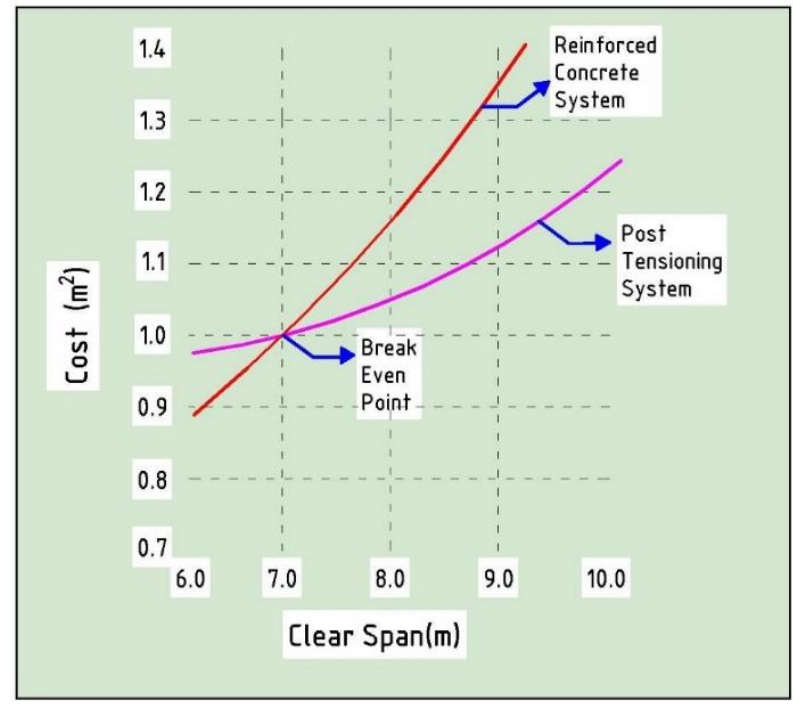

Fig 5. Comparison diagram RC vs PC slabs

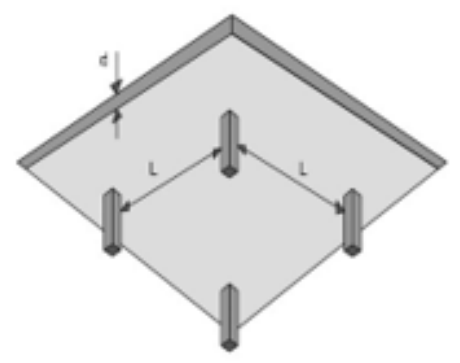

\begin{tabular}{lcc}
\hline & $\begin{array}{c}\text { Total imposed } \\
\text { load } \mathrm{kg} / \mathrm{m}^{2}\end{array}$ & $\begin{array}{c}\text { Span / Depth Ratio } \\
(\mathrm{L} / \mathrm{D})\end{array}$ \\
\hline One span / two way & 500 & 35 \\
Mid span & 500 & 45 \\
Bord span & 500 & 40 \\
\hline
\end{tabular}

Fig 6. Diagram slab thickness vs spans and loading cases

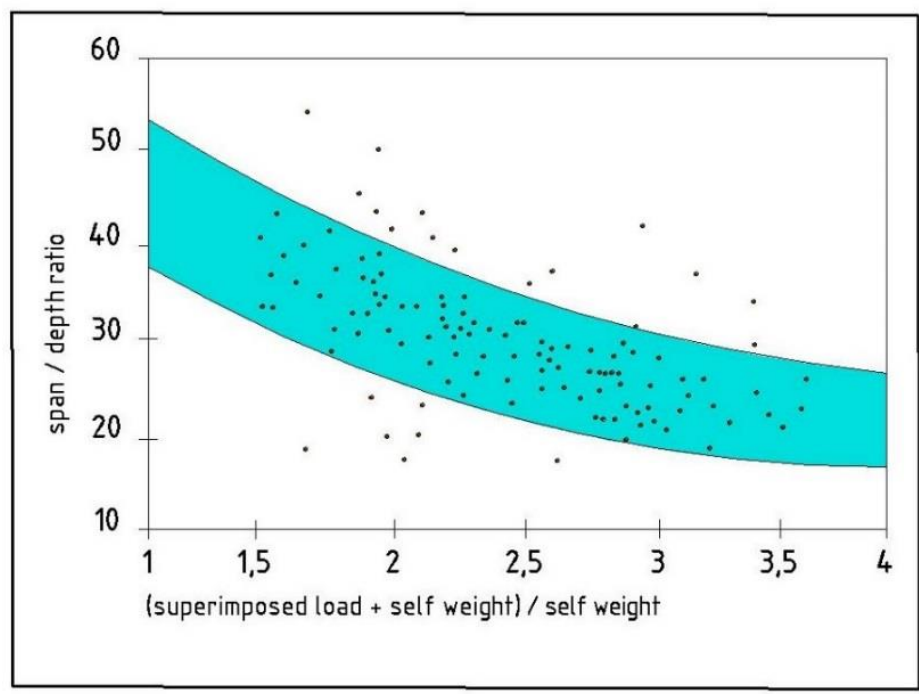

Fig 7. Diagram showing distribution of Span / Depth ratio for imposed load $500-700 \mathrm{~kg} / \mathrm{m}^{2}$ 


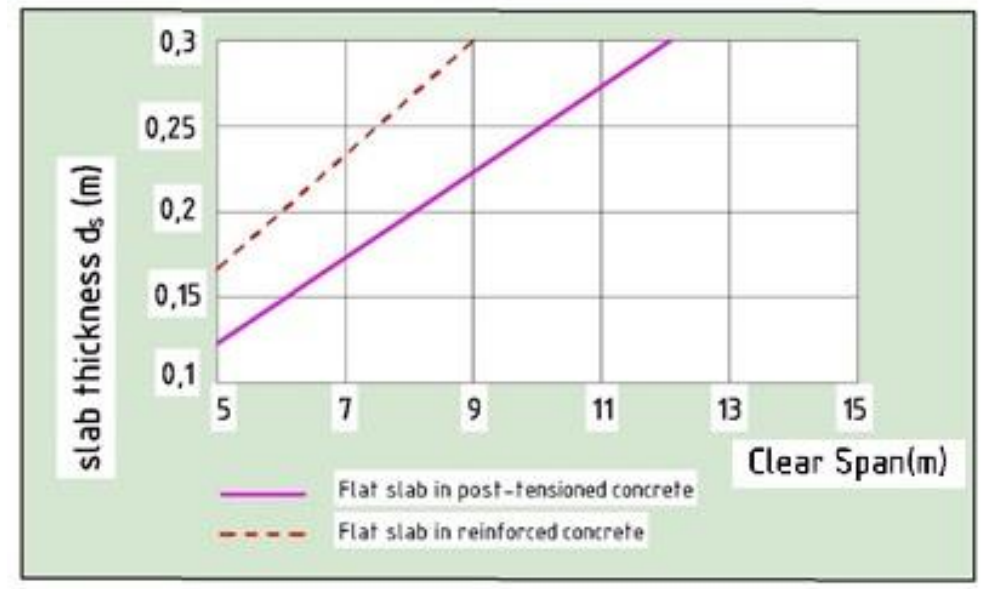

Fig 8. Slab thickness as a function of span lengths (recommended limits slenderness) Comparison diagram of RC vs PC slabs

Dead loads can be calculated by assessing the specified weights and volume as shown on drawings. This means that, in theory, it should be possible to calculate dead loads with a good degree of accuracy. However, structural engineers are sometimes conservative with their estimates, minimizing potential deflections, allowing a margin of error and allowing for alterations over time. As a result, design dead loads often far exceed those experienced in practice

\subsubsection{Live loads (LL)}

Live loads, also known as 'imposed loads', are usually temporary, changeable and dynamic. These include loads such as vehicle traffic, occupants, furniture and other equipment. The intensity of these may vary depending on the time of day. For example, an office building may experience increased live loads during week-day work hours, but much smaller loads during the night or at weekends. Live loads may also be either concentrated or distributed.

\subsection{Deviational forces / amount of prestressing}

\subsubsection{Bending due to sag of tendon}

The approach based on the load- balancing conceptis used for a member with curved parabola formed, tendons and in the analysis of simple and even continuous beams. The moment, upward thrust and upward deflection (camber) due to the prestress in the tendons calculated by prestressing force and the so-called sag of trace of tendon. The upward thrust balances part of the superimposed load.

Take the supported prestressed concrete beam in Fig. 9 subjected to a downward uniformly distributed load of intensity was as example. Let the prestress force be $F$, the span length be $L$ and the sag of the tendon be $h$. If the tendon profile has a uniform curvature, ie., the tendon profile is parabolic, then the equivalent load of the prestress force would be an upward uniformly distributed load of intensity $w_{b}$ per unit length given by:

$w_{b}=\frac{8 F h}{L^{2}}$

\subsubsection{Shear forces / punching}

Punching resistance is another issue which is an important subject in the design of prestressed concrete flat slabs. The punching failure mechanism results from the superposition of shear and flexural stresses near the column. It is a local and brittle failure mechanism.

$\checkmark$ Determination of column dimensions as for preliminary design purpose rules of thumb have been developed as

Column dimensions: $L / w=20$ depending on the loading case. 


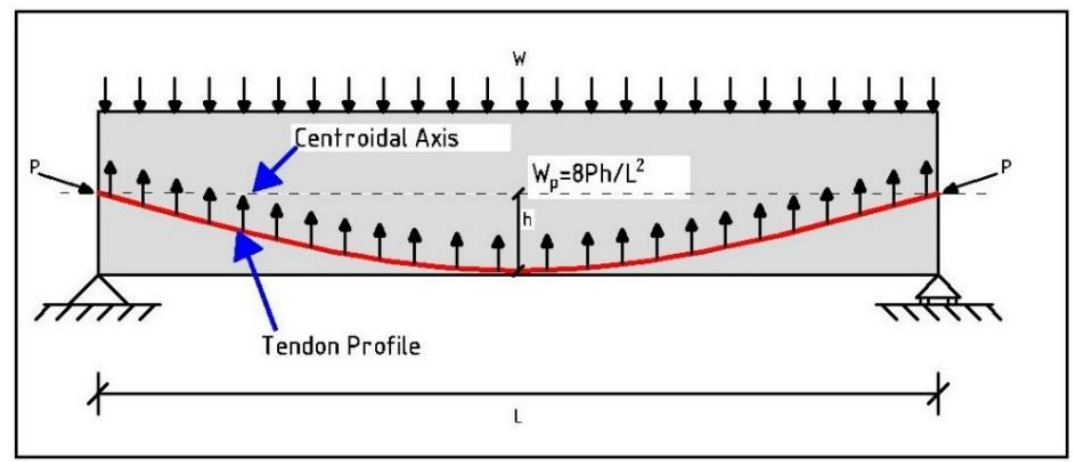

Fig 9. Balancing of external load by prestressing

Instead of using a thicker section, shear reinforcement in the form of shear heads, shear studs or stirrup cages which may be embedded in the slab to enhance shear capacity at the edges of walls and columns in conventional reinforced concrete flat slabs, the deviational forces produced by applying prestressing in the concrete section and balancing the loadings will be transmitted to the punching zone of the column-slab between flexion points and to upper a perfect solution to the punching problems as it can be seen from Fig. 10.

$\checkmark$ On the other hand, as far as the strength is concerned, the dimensions of columns should be enough to carry the column reactions, i.e. the compressional strength of concrete concerned.

\subsection{Location of sag of the tendon}

The moment at the center of the span due to the uniform upward thrust $\left(w_{u p}\right)$ is given by the following equation.

$M=\frac{w_{u p} L^{2}}{8}$

The moment at the center from the prestressing force is given as $M=P h$.

The expression of $w_{u p}$ is calculated by equating the two expressions of $M$. The amount of prestressing force can be calculated from $w_{u p}$ based on elastic analysis.

$P h=\frac{w_{u p} L^{2}}{8}$

In this way, the necessary prestressing force will be be
$P=\frac{w_{u p} L^{2}}{8 h}$

\subsection{Estimation of minimum reinforcement}

The minimum amount of steel reinforcement is defined as that for which 'peak load at first concrete cracking' and 'ultimate load after steel yielding' are equal.

A minimum area of reinforcement is required to control the cracking, which occurs in the concrete due to temperature, shrinkage and creep.

The mild steel reinforcement in either direction in reinforced concrete two sided flat slabs shall not be less than 0.15 percent of the total cross-sectional area.

However, the longitudinal reinforcement of columns compressional member shall not be less than 0.08 percent of the cross-sectional area which is applicable in certain cases for prestressed concrete structures as well as slabs.

\subsection{Amount of prestressing / optimization}

Behavior in service is extremely important for all structures, and serviceability requirements should be central in the choice of the amount of prestressing, in our case particularly for flat slabs.

If the design includes less prestressing, then a larger amount of passive reinforcement will be required. On the other hand, a design calling for more prestressing will lead to smaller amounts of passive reinforcement in order to satisfy safety requirements. 


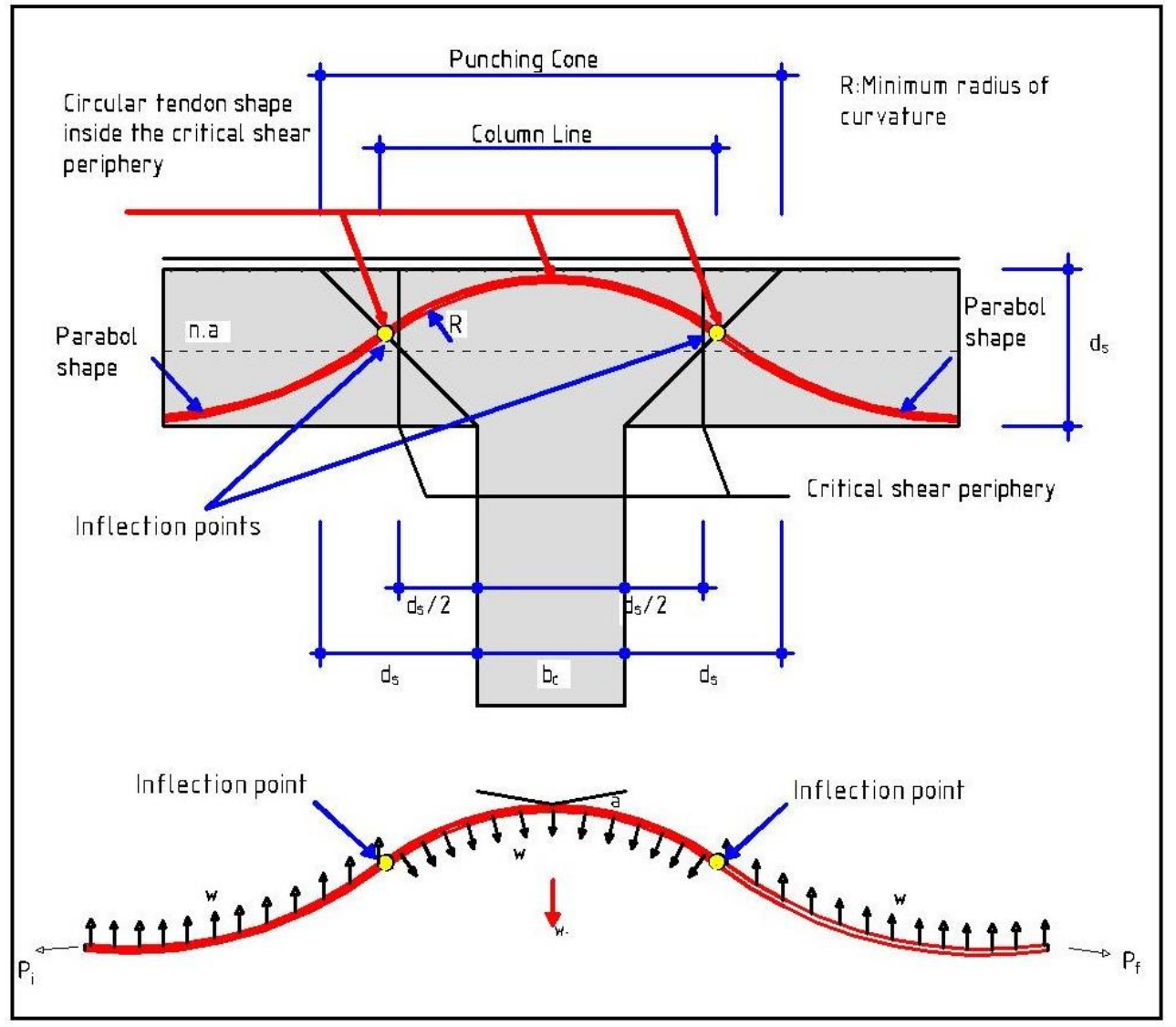

Fig 10. Balancing of Punching Stresses by Prestressing

The final solution frequently combines these requirements with those of economics and - ease ofconstruction depending on the countries with different material prices and workmanship.

In order to attain the most economical combination of RC and PC part, one has to investigate the proportion of the elastic modules of each material (EPC/ERC), but mostly the unit material and erection prices of both tensional members (PPC/PRC).

The factor of proportion EPC/ERC and PPC/PRC play quite an important role to decide the amount of prestressing and mild steel as tensional members. A combination of them with concrete gives an optimum solution as described above. [5]

However, in many cases, a smaller amount of prestressing may lead to a more economical solution, which is also easier to build in the developed countries.

\section{Conclusion}

In spite of intense research in the field of cracking and deformations, there are limited criteria for the choice of the amount of a prestressing in relationship with serviceability requirements. This article proposes the entitled criteria "Structures for the Future - The Search for Quality 595" based on the concept of compensation of deformations, which is essentially a generalization of the loadbalancing method which allows a simple choice of the required amount of pre-stressing and compressive stress values to ensure sufficiently small residual cracks under permanent loads. As a consequence, reliable design criteria should be based on maximum service load not result from considerations under maximum service loads. Rather, the behavior under permanent loads should be the focus of serviceability checks. 
Preliminary design methodology presented in this study depends on the optimal selection of the PC and RC tension members. The optimality here is taken into consideration as a function of cost. Therefore, due to price proportion of PPC/PRC is the main parameter to decide the amount of PC cables. This proportion is lower in industrial countries where PC cables are produces compared to countries where PC cables are imported.

\section{Declaration of conflicting interests}

The author(s) declared no potential conflicts of interest with respect to the research, authorship, and/or publication of this article.

\section{References}

[1] Favre R, Burdet O. Amount of prestressing based on serviceability requirements. IABSE Symposium, 25-27 August 1999, Rio de Janeiro, Brasil.

[2] Goksu E, Jungo A. Export von Schweizer bautechnologie. Freiburger Nachrichten, October 2004, Freiburg, Germany.

[3] Goksu E, Kibar A. Ardgermeli beton teknolojisi. Sheraton Kongre ve Kültür Merkezinde Hotel Nurol Dünyası, March 2005, Ankara, Turkey (in Turkish).

[4] Robertson H (1940) Architecture 1919-1939. Journal of the Royal Society of Arts 88(4557): 449463.

[5] Studer J, Badoux M, Bertogg M, Goksu E, Isler P, Lestuzzi P, Zwicky P (1999) Erdbeben in der westtürkei vom: 17 August 1999. Schweizer Ingenieur und Architekt 43. 